\title{
Information Chaos in Primary Care: Implications for Physician Performance and Patient Safety
}

\author{
John W. Beasley, MD, Tosha B. Wetterneck, MD, MS, Jon Temte, MD, PhD, \\ Jamie A. Lapin, MS, Paul Smith, MD, A. Joy Rivera-Rodriguez, PhD, and \\ Ben-Tzion Karsh, PhD
}

Purpose: The purpose of this article is to explore the concept of information chaos as it applies to the issues of patient safety and physician workload in primary care and to propose a research agenda.

Methods: We use a human factors engineering perspective to discuss the concept of information chaos in primary care and explore implications for its impact on physician performance and patient safety.

Results: Information chaos is comprised of various combinations of information overload, information underload, information scatter, information conflict, and erroneous information. We provide a framework for understanding information chaos, its impact on physician mental workload and situation awareness, and its consequences, and we discuss possible solutions and suggest a research agenda that may lead to methods to reduce the problem.

Conclusions: Information chaos is experienced routinely by primary care physicians. This is not just inconvenient, annoying, and frustrating; it has implications for physician performance and patient safety. Additional research is needed to define methods to measure and eventually reduce information chaos. (J Am Board Fam Med 2011;24:745-751.)

Keywords: Complexity Science, Information Management, Medical Errors, Practice Management, Primary Health Care

Primary care comprises first contact care, longitudinal care, comprehensive care, and coordinated care. ${ }^{1,2}$ Without information that is comprehensive, accessible, timely, and correct, primary care physicians (PCPs) cannot deliver high-quality care.

This article was externally peer reviewed.

Submitted 27 October 2010; revised 23 April 2011; accepted 6 May 2011.

From the Department of Family Medicine (JWB, JT, PS, B-TK), the Department of Industrial and Systems Engineering (JWB, TWB, JAL, B-TK), the Department of Medicine (TBW), School of Medicine and Public Health, University of Wisconsin, Madison, WI, and Clemson University Department of Industrial Engineering (work completed while at the University of Wisconsin [AJR-R]).

Funding: This study was supported in part by grant no. 1P20HS017115 from the Agency for Healthcare Research and Quality (B-TK), grant no. 1R18SH017899 from the Agency for Healthcare Research and Quality (B-TK), and grant no. 1UL1RR025011 from the Clinical \& Translational Science Award Program of the National Center for Research Resources National Institutes of Health.

See Related Article on Page 628
Information problems do exist, ${ }^{3-7}$ with an extrapolation from one study suggesting that errors related to information handling account for $29 \%$ of family medicine errors. ${ }^{8}$ Because information is central to the effectiveness of primary care, we propose a conceptual framework to explain the relationship between information hazards, ie, information problems that may contribute to errors, and PCPs' ability to provide high-quality care.

This framework is especially timely given the emphasis on electronic health record (EHR) use in primary care. The patient-centered medical home

Prior presentation: This was presented as a short talk at the Wonca International Meeting, Cancun, Mexico, May 20, 2010. Two poster presentations at the Family Medicine 40th Anniversary Celebration, Madison, WI, July 16-18, 2010 and the Wisconsin Primary Care Research and Quality Improvement Forum, Middleton, WI, September 16-17, 2010.

Conflict of interest: none declared.

Corresponding author: Ben-Tzion Karsh, Department of Industrial and Systems Engineering, University of Wisconsin-Madison, 1513 University Avenue, Room 3218, Madison, WI 53706 (E-mail: bkarsh@engr.wisc.edu). 
(PCMH) movement encourages EHR implementation to improve information handling. However, EHR systems may not meet this goal. ${ }^{9-11}$ Furthermore, in 2010 the "Meaningful Use" regulations brought incentives and penalties to promote EHR use. ${ }^{12}$ EHRs can transform the quality, comprehensiveness, timeliness, and accessibility of information in both positive and negative ways. ${ }^{13}$ Both the move toward PCMHs and the need to adopt EHRs will have effects on information needs and the design of support systems in primary care. It is therefore important to understand how information relates to primary care.

\section{Information Chaos}

The vignette in Figure 1 illustrates five specific information hazards that arise in primary care and how they can lead to information chaos.

\section{Information Overload}

Information overload occurs when there are too many data (eg, written, verbal and nonverbal, physician's memory) for the clinician to organize, synthesize, draw conclusions from, or act. Primary care involves the integration of an increasing num- ber of patient problems while taking into account family and community factors, ${ }^{1,14,15}$ The PCP care coordination role further adds to the volume of information PCPs must process and on which they must act. ${ }^{2,16,17}$ EHRs may make the situation worse by encouraging electronic copying and pasting, adding irrelevant information through the use of templates, and mixing data needed for billing and legal protection with that needed for clinical care. One physician has called the problem "high-fiber medical records" (Russo P, personal communication, Summer 2008).

\section{Information Underload}

Information underload occurs when necessary information is lacking. The lack of sufficient and available information is common in primary care. ${ }^{18}$ Problems include unavailable or incomplete records or poor recall by the physician or patient. ${ }^{8}$ Patients may decide to not disclose sensitive information. At times, physicians are unaware that information is even available. For example, a physician may prescribe a "new" medication, only to find out later from the patient that he or she had already tried it and stopped use because of a side effect.

Figure 1. A clinical vignette illustrating information hazards.

\section{Clinical Vignette Illustrating Information Hazards}

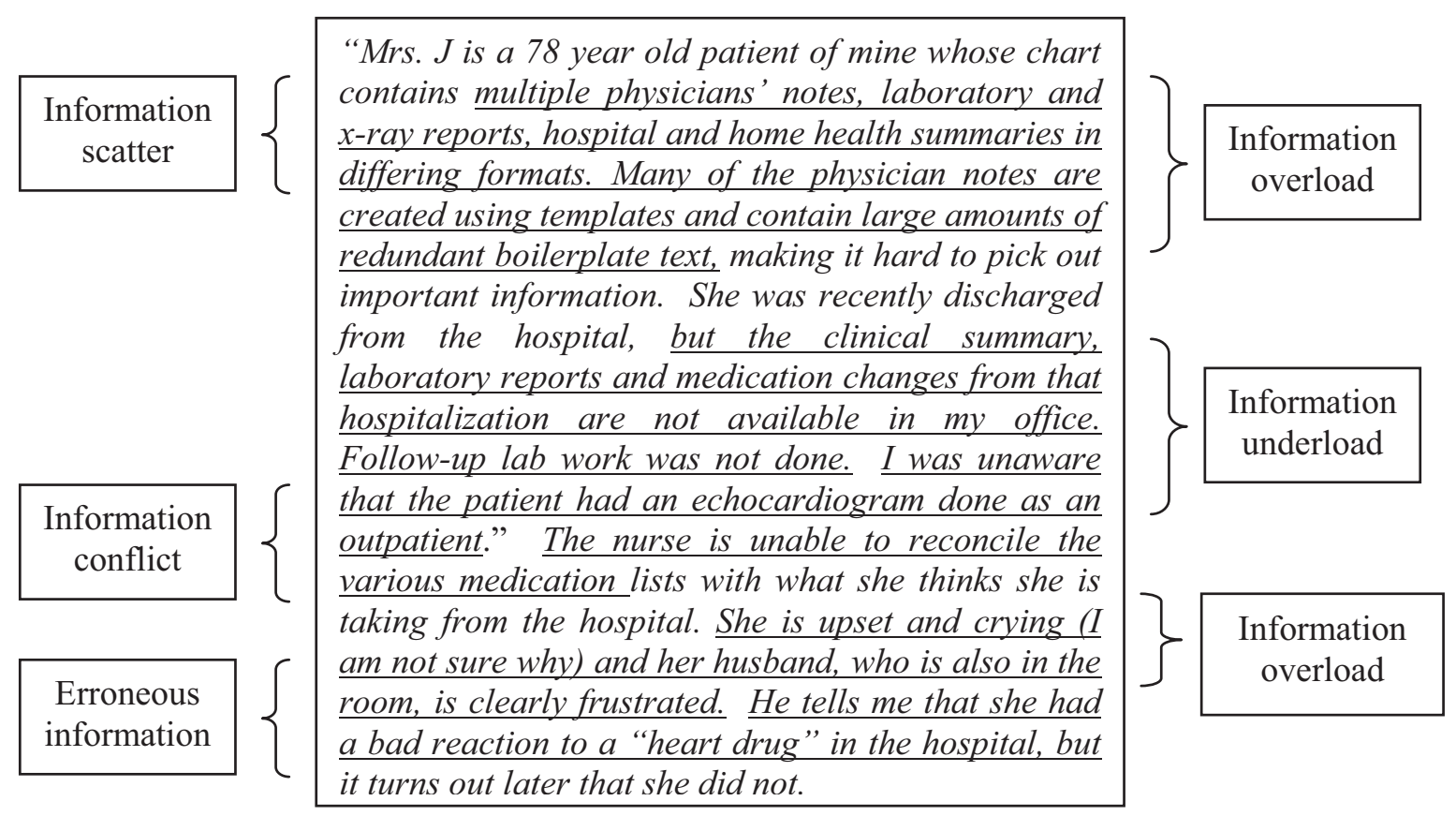


Although this information may be in the chart, the physician may have not known it was there. Information that is theoretically "in the chart," but not readily accessible, is, for all intents and purposes, invisible.

\section{Information Scatter}

Information scatter refers to having information located in multiple places. During any given primary care encounter, the needed information may be located on the intake form, in the paper chart or EHR, at the clinic of a consultant or a hospital, or in the patient's or the clinician's mind. Though EHRs may reduce the problem of information scatter, ${ }^{19}$ they can also worsen the problem because inadequate search methods are used to find information quickly and effectively. ${ }^{13}$

\section{Information Conflict}

Information conflict occurs when the clinician is unable to determine which data are correct. The clinician often is confronted with a variety of conflicting data regarding an issue. For example, the patient may think he or she is on one medication, the clinic record suggests a different one, and the hospital discharge note states yet another.

\section{Erroneous Information}

Erroneous information is when the information is wrong, eg, the patient tells the doctor he or she is taking aspirin for pain when in fact he or she is taking acetaminophen or information is entered into the wrong patient chart. ${ }^{4}$ When incorrect information gets into a record it may be hard to purge it or it may simply get replicated by clinicians without validating it with the patient. ${ }^{20}$

We conceptualize these five information hazards: information overload, underload, scatter, conflict, and erroneous information, as information chaos. Separately or together, these hazards increase the risk of an information-related error and are experienced by primary care clinicians on a daily basis. Though the concept of information chaos resonates with PCPs, the nature of information chaos and the factors that can affect the relationship between it and patient outcomes have not been explored in primary care and are likely underappreciated by clinicians, administrators, and EHR programmers and planners. Information chaos is more than inconvenient, annoying, and frustrating; there are operational implications that can impair physician performance, increase workload, and reduce the safety and quality of care delivered.

\section{Consequences of Information Chaos}

The field of human factors engineering and ergonomics (HFE) ${ }^{21-24}$ contributes to our understanding of information chaos. HFE studies and applies information about human cognitive and physical limitations and human abilities to the design of systems, including, for example, work processes, tools, technologies, and environments; in turn HFE studies how systems impact human cognitive and physical performance. From HFE science, we hypothesize a conceptual framework for the way information chaos relates to the cognitive processes in primary care; this is presented in Figure 2.

Information chaos imposes demands on PCPs. Because of information overload, they may not be able to adequately review all the information and may miss important details. Because of information underload, scatter, and conflict, PCPs must expend effort searching through charts, phone calls, further questions to the patient, and perhaps unnecessary testing for needed information. Erroneous information may lead to re-work, errors in diagnosis, or treatment decisions that threaten patient safety. The work PCPs do in response to information chaos does not add value to the patient visit; it is only necessary to deal with the chaos. Importantly, it distracts the PCP from the primary work of the visit: caring for the patient.

From a cognitive point of view, information chaos may contribute to two unwanted outcomes: impaired situational awareness $(\mathrm{SA})^{25-30}$ and in-

Figure 2. Information chaos, mental workload, situational awareness, moderators, and influences.

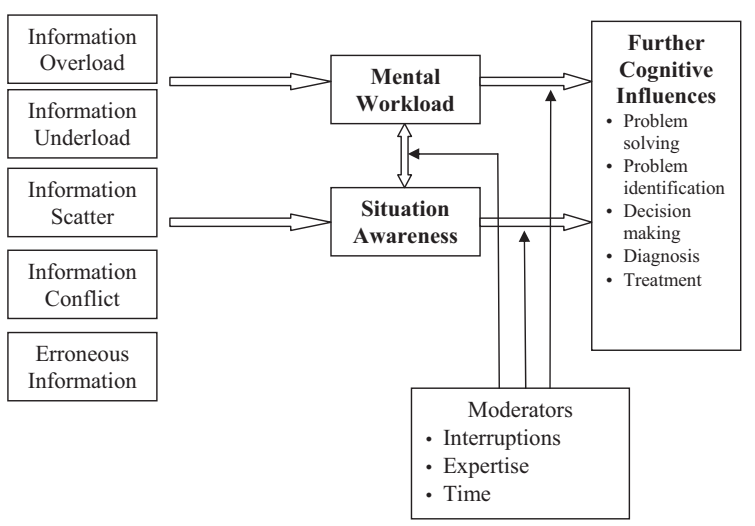


creased mental workload. ${ }^{31-33} \mathrm{SA}$ is defined as a person's awareness and understanding of his or her task-related situation. It has three levels: (1) perception of elements in the environment, eg, patient cues/stimuli (pulse, color), chart, EHR, nurse; (2) comprehension of the meaning of those elements by integrating the disparate pieces of information and determining what is important; and (3) projection of future status so that decisions can be made. ${ }^{25,34}$ Whether or not accurate SA is achieved depends on the timing, comprehensiveness, accessibility, and quality of the information obtained. That means information chaos can directly impair SA. If SA is poor, it can result in impaired decision making. ${ }^{25,26,29,30,35}$

A related variable is mental workload, which is the amount of cognitive resources required for a task. Mental workload is a function of demand, which may be increased because of information chaos, and available resources, such as time. ${ }^{31,33}$ Mental workload and SA are related. Poor SA increases mental workload, and high mental workload can degrade SA. ${ }^{36}$ High mental workload among physicians occurs when the mental demands imposed on the physician exceed the physician's resources to cope with those demands. Both the poor SA and the high mental workload generated by information chaos can impair cognitive work ${ }^{29,31,33,35}$ (eg, diagnosis and treatment decisions) and may have negative impacts on safety. ${ }^{35}$

At the start of an office visit, a PCP will have some $\mathrm{SA}$, but it is incomplete. The clinician only knows what he or she remembers from previous visits, from a brief look at the patient's chart, and possibly from a short meeting with the nurse who placed the patient in the examination room. As soon as the clinician enters the room, SA is dynamically updated based on sensory inputs such as how the patient looks, feels, and sounds and from higher level processes such as communication with the patient and searching in the medical record. Whether or not accurate SA is achieved is dependent on the timing and quality of the information obtained through sensation, perception, communication, and record searching. Because of information chaos, the clinician may never fully develop SA and, because of information underload, may not even know they are not fully or accurately aware of the situation, as is suggested by work in related fields. ${ }^{37}$

During times of high mental workload, which may be increased by information chaos, people involun- tarily focus on fewer cues, considering fewer options and solutions because of cognitive tunneling. ${ }^{32}$ This occurs when people zoom in on a narrow set of cues or options because mentally they cannot handle more. In such situations, people are at risk for decision errors $^{38}$ because they miss things they should have noticed, such as patient symptoms or abnormal laboratory test results. In other words, in situations of high mental workload, people operate with selective and reduced capacity. ${ }^{32}$ Among PCPs, higher mental workload has been positively associated with a higher perceived probability of medical error. ${ }^{39}$

\section{Factors Affecting Information Chaos and Their Consequences}

The magnitude of the effects of information chaos on the quality of care delivered by PCPs is affected by a variety of moderators. We highlight three that affect the relationship: interruptions, physician expertise, and time.

\section{Interruptions}

Interruptions occur when something or someone in the environment unexpectedly disrupts the physician's physical or mental workflow. ${ }^{40-42}$ This may shift the physician's attention from the task in which he or she was originally engaged - the primary task-to the interrupting task. ${ }^{43}$ Once this shift in attention occurs, memory of the primary task begins to decay to make room for the processes required to deal with the interrupting task. ${ }^{44}$ Many interruptions are unnecessary, such as EHR systems that impede the flow of the physician-patient conversation. ${ }^{45}$ Interruptions may increase mental workload, reduce the ability to cope with information chaos, and thereby potentially impair performance.

\section{Expertise}

Expertise is another variable that affects the relationship between information chaos and its consequences. ${ }^{46}$ It is probable that a PCP with more expertise can handle more information chaos, maintain better SA, and have less mental workload than a PCP with less expertise. With experience comes more accurate expectations about what is going on, where information resides, and what ambiguous or confusing information implies. Because of that, the same level of information chaos may have less impact on a more experienced clinician. 


\section{Time}

Finally, the time available to cope with information chaos is important for patient safety. Physicians working for organizations that allow them to schedule patient visits with sufficient time to manage their patients' problems will suffer fewer effects of information chaos; they can take the time to deal with the situation. On the other hand, when information chaos occurs in a time-constrained environment (eg, during a 15-minute visit for a patient with several chronic conditions and medications to manage), the impact on physician performance is exacerbated. Time is perhaps the most important resource available to deal with information chaos.

\section{What Can be Done to Calm The Chaos?}

Reducing information chaos requires mechanisms to ensure that the necessary information is available and presented in a useable manner at the right time. Two general strategies have been proposed to calm the chaos: visit preparation and EHRs.

\section{Visit Preparation}

PCPs need to know the reason(s) for a patient visit. Clinics may have patients complete some type of "patient agenda" form, either electronic or on paper, before the visit. Another approach is the teamlet, ${ }^{47}$ or huddle, ${ }^{48}$ in which the nurse who places the patient in the examination room meets briefly with the PCP to talk about the patient's stated or written agenda. Using more staff support to assist in obtaining and organizing information during the visit has been proposed, as well. ${ }^{49}$ This is a good start, but at best it only lets the PCP know the agenda mere minutes before he or she enters the room, and there may not be time to obtain needed information from external sources or to review information in depth.

\section{Electronic Health Records}

EHRs contribute to more timely and available information but caveats exist, many of which have been discussed. ${ }^{11,45}$ EHRs generally are designed to facilitate data entry to conduct and document the process of care. As more and more data are available in an EHR, there is an even greater need for improved search methods and display techniques to present the data needed at the time of the patient visit. Ideal EHR design would allow relevant, needed information to be pushed to the clinician based on the reasons for the visit.

\section{A Research Agenda to Explore Information Chaos in Primary Care}

Our hypothesis is that appropriate practice redesign will reduce information chaos and provide the PCP with needed SA during all phases of the visit, allowing him or her make better care decisions and accomplish more (and perhaps with less fatigue) than would otherwise be the case. More research is needed to determine just what this practice redesign should be.

We propose that if progress is to be made on controlling information chaos and its effects on physician performance, the following questions, at minimum, need to be addressed:

1. Which aspects of information chaos are most common and which pose the greatest threats to patient safety?

2. How can we measure and quantify the elements of information chaos or resulting behaviors to determine the success of an intervention?

3. What interventions can reduce the information hazards and lead to the greatest improvements in SA, mental workload, and ultimately patient safety?

4. What are valid ways to measure SA in the health care settings? Our team had to develop new measures because none existed specific to primary care and measuring SA during actual patient care delivery is challenging.

5. What is the nature of the effects of the moderators? Can clinician expertise or patient scheduling help to address information chaos?

6. When is the right time to provide information and what is the right information to provide to PCPs so that they can prepare appropriately for a visit and reduce information chaos?

7. What is the role of the clinic staff, patients, and caregivers to prepare information for a PCP visit? When is the right time to collect the information and how should it be presented?

The questions above are examples of what needs to be done to help improve primary care. Technology cannot alone solve the problems of information chaos or the transformation to a PCMH. New thinking is necessary. We cannot accept that infor- 
mation chaos is "just the way primary care is." If we do this, we are not taking advantage of primary care redesign and the power of information systems to maximize the quality and efficiency of patient care delivery.

\section{References}

1. Donaldson MS, Yordy KD, Lohr KN, Vanselow NA. Primary Care: America's Health in a New Era. Washington, D.C.: National Academies Press; 1996.

2. Starfield B. Primary care. J Ambul Care Manage 1993;16(4):27-37.

3. Elder NC, Graham D, Brandt E, et al. The testing process in family medicine: problems, solutions and barriers as seen by physicians and their staff: a study of the American Academy of Family Physicians' Research Network. J Patient Saf 2006;2(3):25-32.

4. Kuzel AJ, Woolf SH, Gilchrist VJ, et al. Patient reports of preventable problems and harms in primary health care. Ann Fam Med 2004;2(4):333-40.

5. Phillips RL, Dovey SM, Graham D, Elder NC, Hickner J. Learning from different lenses: reports of medical errors in primary care by clinicians, staff, and patients: a project of the American Academy of Family Physicians National Research Network. J Patient Saf 2006;2(3):140-6.

6. Kuo GM, Phillips RL, Graham D, Hickner JM. Medication errors reported by US family physicians and their office staff. Qual Saf Health Care 2008; 17(4):286-90.

7. Makeham MA, Stromer S, Bridges-Webb C, et al. Patient safety events reported in general practice: a taxonomy. Qual Saf Health Care 2008;17(1):53-7.

8. Dovey SM, Meyers DS, Phillips RL, et al. A preliminary taxonomy of medical errors in family practice. Qual Saf Health Care 2002;11(3):233-8.

9. Nutting PA, Miller WL, Crabtree BF, Jaen CR, Stewart EE, Stange KC. Initial lessons from the first national demonstration project on practice transformation to a patient-centered medical home. Ann Fam Med 2009;7(3):254-60.

10. Fernandopulle R, Patel N. How the electronic health record did not measure up to the demands of our medical home practice. Health Aff (Millwood) 2010;29(4):622-8.

11. Karsh BT, Weinger MB, Abbott PA, Wears RL. Health information technology: fallacies and sober realities. J Am Med Inform Assoc 2010;17(6):617-23.

12. Centers for Medicare \& Medicaid Services (CMS), HHS. Medicare and Medicaid programs; electronic health record incentive program. Final rule. Fed Regist 2010;75(144):44313-62.

13. Schiff GD, Bates DW. Can electronic clinical documentation help prevent diagnostic errors? N Engl J Med 2010;362(12):1066-9.

14. Beasley JW, Hankey TH, Erickson R, et al. How many problems do family physicians manage at each encounter? A WReN study. Ann Fam Med 2004;2: 405-10.

15. Abbo ED, Zhang Q, Zelder M, Huang ES. The increasing number of clinical items addressed during the time of adult primary care visits. J Gen Intern Med 2008;23(12):1058-65.

16. Bodenheimer T. Coordinating care-a perilous journey through the health care system. N Engl J Med 2008;358(10):1064-71.

17. Pham HH, O'Malley AS, Bach PB, Saiontz-Martinez C, Schrag D. Primary care physicians' links to other physicians through Medicare patients: the scope of care coordination. Ann Intern Med 2009; 150(4):236-42.

18. Smith PC, Rodrig AG, Bublitz C, et al. Missing clinical information during primary care visits. JAMA 2005;293:565-71.

19. Institute of Medicine (ed). Crossing the quality chasm: a new health system for the 21 st century. Washington, D.C.: National Academies Press; 2001.

20. Thielke S, Hammond K, Helbig S. Copying and pasting of examinations within the electronic health record. Int J Med Inform 2007;76S:S122-8.

21. Beasley JW, Hamilton-Escoto K, Karsh B. Human factors in primary care. In: Carayon P (ed). Handbook of Human Factors and Ergonomics in Patient Safety. Mahwah, NJ: Lawrence Erlbaum Associates; 2006:921-36.

22. Salvendy G (ed). Handbook of Human Factors and Ergonomics. 2nd ed. Hoboken, NJ: John Wiley and Sons; 1997.

23. Sanders MS, McCormick EJ. Human Factors in Engineering and Design. 7th ed. New York: McGrawHill Science; 1993.

24. Wickens CD, Lee JD, Liu Y, Gordon-Becker S. An Introduction to Human Factors Engineering. 2nd ed. Upper Saddle River, NJ: Pearson Education; 2004.

25. Endsley MR. Towards a theory of situation awareness in dynamic systems. Hum Factors 1995;37:32-64.

26. Hazlehurst B, McMullen CK, Gorman PN. Distributed cognition in the heart room: how situation awareness arises from coordinated communications during cardiac surgery. J Biomed Inform 2007;40(5): 539-51.

27. Hogan MP, Pace DE, Hapgood J, Boone DC. Use of human patient simulation and the Situation Awareness Global Assessment Technique in practical trauma skills assessment. J Trauma 2006;61(5): 1047-52.

28. Salmon PM, Stanton NA, Walker GH, Jenkins D, Baber C, McMaster R. Representing situation awareness in collaborative systems: a case study in the energy distribution domain. Ergonomics 2008; 51(3):367-84.

29. Smith K, Hancock PA. Situation awareness is adaptive, externally directed consciousness. Hum Factors 1995;37(1):137-48. 
30. Stanton NA, Stewart R, Harris D, et al. Distributed situation awareness in dynamic systems: theoretical development and application of an ergonomics methodology. Ergonomics 2006;49(12-13):1288-311.

31. Hancock PA, Hoffman JE. Stress and cognitive workload. In: National Research Council (ed). Tactical display for soldiers: human factors considerations. Washington, D.C.: National Academies Press; 1997:129-62.

32. Hancock PA, Szalma JL. Operator stress and display design. Ergon Des 2003;11(2):13-8.

33. Hancock PA, Warm JS. A dynamic model of stress and sustained attention. Hum Factors Oct 1989; 31(5):519-37.

34. Endsley MR, Garland DJ (eds). Situation Awareness Analysis and Measurement. Hillsdale, NJ: Lawrence Erlbaum Associates; 2000.

35. Stanton NA, Chambers PRG, Piggott J. Situational awareness and safety. Saf Sci 2001;39(3): 189-204.

36. Hancock PA, Desmond PA (eds). Stress, workload and fatigue. Boca Raton, FL, CRC Press; 2000.

37. Endsley MR, Jones DG. Disruptions, Interruptions, and information attack: impact on situation awareness and decision making. Paper presented at: 45 th Annual Meeting, Human Factors and Ergonomics Society Annual Meeting, October 8-12, 2001, Minneapolis, MN.

38. Kahneman D, Tversky A, Slovic P. Judgement under Uncertainty: Heuristics and Biases. Cambridge, UK: Cambridge University Press; 1982.

39. Temte J, Grasmick M, O'Halloran P, et al. Mental workload in primary care. Paper presented at: AAFP National Research Network 8th Annual Convocation of Practices and Networks, March 7-9, 2008, Colorado Springs, CO.
40. Brixey JJ, Robinson DJ, Johnson CW, Johnson TR, Turley JP, Zhang J. A concept analysis of the phenomenon interruption. ANS Adv Nurs Sci 2007; 30(1):E26-42.

41. Chisholm CD, Dornfeld AM, Nelson DR, Cordell WH. Work interrupted: a comparison of workplace interruptions in emergency departments and primary care offices. Ann Emerg Med 2001;38(2): 146-51.

42. Paxton F, Heaney D, Howie J, Porter BA. A study of interruption rates for practice nurses and GPs. Nurs Stand 1996;10(43):33-6.

43. Potter P, Wolf L, Boxerman S, et al. Understanding the cognitive work of nursing in the acute care environment. J Nurs Adm 2005;35(7-8):327-35.

44. Altmann EM, Trafton JG. Task Interruption: Resumption Lag and the Role of Cues. Proceedings of the 26th Annual Conference of the Cognitive Science Society; 2004:42-7.

45. Zheng K, Haftel HM, Hirschl RB, O'Reilly M, Hanauer DA. Quantifying the impact of health IT implementations on clinical workflow: a new methodological perspective. J Am Med Inform Assoc 2010;17(4):454-61.

46. Hancock PA, Weaver JL. On time distortion under stress. Theoretical Issues in Ergonomic Science 2006;6(2):193-211.

47. Bodenheimer T, Laing BY. The teamlet model of primary care. Ann Fam Med 2007;5(5):457-61.

48. Stewart EE, Johnson BC. Improve your office efficiency in mere minutes. Fam Pract Manag 2007;14: 27-9.

49. Sinsky CA. Improving office practice: working smarter, not harder. Fam Pract Manag 2006;13(10): 28-34. 